\title{
Wheelchair Tire Device
}

National Cancer Institute

\section{Source}

National Cancer Institute. Wheelchair Tire Device. NCI Thesaurus. Code C51069.

A tire designed to be mounted on a wheelchair wheel. 